\title{
Non-hematopoietic IL-4Ra expression contributes to fructose-driven obesity and metabolic sequelae
}

\author{
Michelle S. M. A. Damen (iD ${ }^{1,2}$, Traci E. Stankiewicz ${ }^{1,2}$, Se-Hyung Park ${ }^{3}$, Robert N. Helsley (iD) ${ }^{3}$, Calvin C. Chan (iD ${ }^{1,2,4,5}$, \\ Maria E. Moreno-Fernandez ${ }^{1,2}$, Jessica R. Doll $\mathbb{D}^{1,2}$, Sara Szabo ${ }^{1,6}$, De'Broski R. Herbert ${ }^{7}$, Samir Softic ${ }^{3,8}$ and Senad Divanovic (D) ${ }^{1,2,4,5,9}{ }^{凶}$
}

(c) The Author(s) 2021

\begin{abstract}
OBJECTIVE: The risks of excess sugar intake in addition to high-fat diet consumption on immunopathogenesis of obesityassociated metabolic diseases are poorly defined. Interleukin-4 (IL-4) and IL-13 signaling via IL-4Ra regulates adipose tissue lipolysis, insulin sensitivity, and liver fibrosis in obesity. However, the contribution of IL-4Ra to sugar rich diet-driven obesity and metabolic sequelae remains unknown.

METHODS: WT, IL-4Ra-deficient (IL-4Ra ${ }^{-1-}$ ) and STAT6-deficient mice (STAT6 ${ }^{-1-}$ ) male mice were fed low-fat chow, high fat (HF) or $\mathrm{HF}$ plus high carbohydrate ( $\mathrm{HC} /$ fructose) diet $(\mathrm{HF}+\mathrm{HC})$. Analysis included quantification of: (i) body weight, adiposity, energy expenditure, fructose metabolism, fatty acid oxidation/synthesis, glucose dysmetabolism and hepatocellular damage; (ii) the contribution of the hematopoietic or non-hematopoietic IL-4Ra expression; and (iii) the relevance of IL-4Ra downstream canonical STAT6 signaling pathway in this setting.

RESULTS: We show that IL-4Ra regulated HF + HC diet-driven weight gain, whole body adiposity, adipose tissue inflammatory gene expression, energy expenditure, locomotor activity, glucose metabolism, hepatic steatosis, hepatic inflammatory gene expression and hepatocellular damage. These effects were potentially, and in part, dependent on non-hematopoietic IL-4Ra expression but were independent of direct STAT6 activation. Mechanistically, hepatic ketohexokinase-A and C expression was dependent on IL-4Ra, as it was reduced in IL-4Ra-deficient mice. KHK activity was also affected by HF + HC dietary challenge. Further, reduced expression/activity of KHK in IL-4Ra mice had a significant effect on fatty acid oxidation and fatty acid synthesis pathways.
\end{abstract}

CONCLUSION: Our findings highlight potential contribution of non-hematopoietic IL-4Ra activation of a non-canonical signaling pathway that regulates the HF $+\mathrm{HC}$ diet-driven induction of obesity and severity of obesity-associated sequelae.

International Journal of Obesity (2021) 45:2377-2387; https://doi.org/10.1038/s41366-021-00902-6

\section{INTRODUCTION}

Obesity is a major risk factor for development of common, serious medical conditions including low-grade chronic inflammation, insulin resistance, type II diabetes (T2D) and non-alcoholic fatty liver disease (NAFLD) [1]. Over the last few decades, intake of carbohydrates via sugar sweetened food coupled with high-fat (HF) diet consumption has greatly increased. While the general effects of HF diet feeding in experimental models of obesity are well understood, risks of excess sugar (e.g., glucose, sucrose, fructose) intake in addition to HF diet consumption are not well defined. Like HF diet, increased consumption of sugars, specifically high-fructose containing goods, promotes obesity-related sequelae [2]. Both fructose and glucose are 6-carbon sugars, however cellular metabolism of these sugars is divergent. Ubiquitous cellular processing of glucose in the body triggers strong insulin secretion. In contrast, fructose is mainly processed by the liver and only triggers minor insulin secretion. In addition, fructose potentially promotes hepatic triglyceride (TG) accumulation, hepatic de novo lipogenesis (DNL) [3], contributes to (hepatic) insulin resistance [4], and causes mitochondrial dysfunction and inflammation $[5,6]$.

The immune system is a key pathogenic link between obesity and obesity-associated sequelae [7]. Traditionally, studies have focused on the impact of proinflammatory cytokines (e.g., IL-6, TNF, IL-1, IL-17) while the role of anti-inflammatory cytokines (e.g., IL-4, IL-10, IL-13) in these settings remains insufficiently understood $[7,8]$. Further, whether and how fructose impacts antiinflammatory cytokine production and function in obesityassociated sequelae is not known.

IL-4, a short four a-helix bundle secreted glycoprotein, is a pleiotropic cytokine primarily produced by activated $\mathrm{T}$ helper (Th2) cells and eosinophils. IL-4 impacts function of various immune cells including macrophages (e.g., polarization,

\footnotetext{
${ }^{1}$ Department of Pediatrics, University of Cincinnati College of Medicine, Cincinnati, OH, USA. ${ }^{2}$ Division of Immunobiology, Cincinnati Children's Hospital Medical Center, Cincinnati, OH, USA. ${ }^{3}$ Division of Gastroenterology, Hepatology, and Nutrition, Department of Pediatrics, University of Kentucky College of Medicine and Kentucky Children's Hospital, Lexington, KY, USA. ${ }^{4}$ Medical Scientist Training Program, University of Cincinnati College of Medicine, Cincinnati, OH, USA. ${ }^{5}$ Immunology Graduate Program, Cincinnati Children's Hospital Medical Center and the University of Cincinnati College of Medicine, Cincinnati, OH, USA. ${ }^{6}$ Division of Pathology, Cincinnati Children's Hospital Medical Center, Cincinnati, OH, USA. ${ }^{7}$ Department of Pathobiology, University of Pennsylvania School of Veterinary Medicine, Philadelphia, PA, USA. ${ }^{8}$ Department of Pharmacology and Nutritional Sciences, University of Kentucky College of Medicine, Lexington, KY, USA. ${ }^{9}$ Center for Inflammation and Tolerance, Cincinnati Children's Hospital Medical Center, Cincinnati, OH, USA. ${ }^{凶}$ email: senad.divanovic@cchmc.org
} 
inflammatory responsiveness), $T$ cells (e.g., expansion, differentiation, cytokine production) and B cells (e.g., isotype class switching from $\lg M$ to $\lg G 1$ and $\operatorname{lgE}$ ) $[9,10]$. IL-4 signals through its specific type I or type II receptors on the cell surface. The type I receptor consists of $140-\mathrm{kDa}$ binding chain, the a chain (IL-4Ra) and the IL-2 receptor common $\gamma$ chain $(\gamma c)$ [11]. The type II receptor is established when the IL-4Ra chain forms a complex with the IL-13R chain a1 (IL-13Ra1) [12-14]. The interaction between these two subunits defines IL-4 and IL-13 functional overlap in several biological processes. IL-4 high affinity binding to the IL-4Ra promotes interaction with either the common $\gamma$ chain or the IL-13R chain a1. As these subunits share equal affinity for the IL-4:IL-4Ra complex the activation of the downstream signaling pathway depends on the specific chain expression on the cell surface $[15,16]$.

The IL-4RA gene is located on chromosome 16p (16p12.1) in humans and chromosome 7 in mice [17]. IL-4Ra expression is detected in various tissues (e.g., liver, brain, lung, heart, kidney, adipose tissue) and cells (e.g., T cells, B cells, macrophages, epithelial cells, adipocytes). HF diet feeding augmented ex vivo IL-4 secretion by splenocytes [18], white adipose tissue (WAT) inflammation [19], and the severity of obesity-associated sequelae - the latter dependent on IL-4Ra-driven STAT6 activation [20]. IL-4 increases lipolysis by altering hormone sensitive lipase adipogenic/lipolytic activity [21]. Further, it is proposed that IL-4 drives AT browning and energy expenditure (EE) via increased peroxisome proliferatoractivated receptor gamma coactivator 1-alpha (PGC-1a) and uncoupling protein 1 (UCP-1) expression in WAT and release of catecholamines by alternatively activated macrophages [22]. However, a subsequent robust mechanistic study demonstrated that alternatively activated macrophages were incapable of synthesizing sufficient amounts of catecholamines to stimulate adipocyte metabolism or thermogenesis and that alterations in the metabolic phenotype of mice could have impacted developmental processes or sympathetic regulation of genes expressed in the nervous system [23].

Given the rapidly increasing prevalence of combined HF and sugar intake and the large diversity in findings on the role of IL-4 in obesity-associated sequelae, we examined the role of IL-4Ra in a combined $\mathrm{HF}$ and high carbohydrate/fructose $(\mathrm{HC})$ diet-induced obesity model ( $\mathrm{HF}+\mathrm{HC})$ - a model that more closely mimics obesity disease. Here we demonstrate that $\mathrm{HF}+\mathrm{HC}$ diet feeding augmented the occurrence of obesity-associated sequelae via engagement of non-hematopoietic IL-4Ra expression. The effect on weight gain and glucose dysmetabolism in this setting were independent from the canonical IL-4Ra-driven activation of STAT6. IL-4Ra impacted hepatic ketohexokinase-C (KHK-C) and KHK-A expression/activity and correlated with altered hepatic fatty acid oxidation (FAO), fatty acid synthesis (FAS) and hepatic TG accumulation in IL-4Ra-deficient mice fed HF $+\mathrm{HC}$ diet. Collectively, our findings demonstrate that the non-hematopoietic IL$4 \mathrm{Ra}$ expression is important contributor to combined $\mathrm{HF}+\mathrm{HC}$ diet-driven obesity.

\begin{abstract}
METHODS

\section{Mice}

All mice used were age-matched males on a C57BL/6 background (Jackson). WT, IL-4Ra deficient (IL-4Ra ${ }^{-1-}$ ) and STAT6-deficient (STAT6 ${ }^{-1-}$ ) [24] mice were bred at Cincinnati Children's Hospital Medical Center (CCHMC) in a specific pathogen-free (spf) facility maintained at $22^{\circ} \mathrm{C}$. For the proposed experiments involved, we will use groups sized based on previous studies with HF diet models which suggest that around $n=6$ mice per group are sufficient to detect statistically significant differences.
\end{abstract}

\section{Obesogenic diet model}

All diet-induced obesity (DIO) studies were performed as previously described [25-28] with animals being fasted overnight prior to glucose tolerance tests, and terminal harvests. Briefly, 6-8 weeks old mice were started on a diet and were fed either an autoclaved low-fat chow diet food (LAB Diet \#5010 (CD); calories provided by carbohydrates (58\%), fat (13\%) and protein (29\%), irradiated high-fat diet (HF; Research Diets \#D12492; 20\% protein Casein, Lactic, 30 Mesh, Cystine, L; 20\% carbohydrate, Lodex 10, Sucrose, Fine Granulated; Fiber; and $60 \%$ of calories from fat, Lard, Soybean Oil, USP; Mineral mix S10026B; Vitamin Choline Bitartrate and mix V10001C; energy density $5.21 \mathrm{Kcal} / \mathrm{g}$ ) or a high-fat high carbohydrate diet (HF Research Diets \#D12492i $+\mathrm{HC}$ drinking water [HF $+\mathrm{HC}]$ ). The $\mathrm{HC}$ drinking water is a total of $42 \mathrm{~g} / \mathrm{L}$ of carbohydrates mixed at a ratio of $45 \%$ sucrose (Fisher \#BP220-1) and 55\% fructose (Acros \#161350010) by weight, as previously shown [29]. Food and water were replenished weekly. For all studies body weight, food consumption and total caloric intake per mouse were quantified weekly. Total fat mass and lean mass were determined by nuclear magnetic resonance (Whole Body Composition Analyzer; Echo MRI) [30]. In addition, glucose and insulin tolerance tests (ITT) were done as previously described [26]. Energy expenditure (EE) was measured by Phenomaster (TSE systems) as previously described [27]. By having multiple mice in each group data points show biological replicates.

\section{Quantification of cytokine levels}

For quantification of LPS-driven cytokine production in vivo, mice were injected with capture antibodies i.p. $3 \mathrm{~h}$ prior to LPS (i.p. $25 \mu \mathrm{g} / \mathrm{mouse}$ ) challenge, and serum cytokine levels were determined $4 \mathrm{~h}$ later using in vivo cytokine capture assay (IVCCA) as previously described $[24,25,27,31]$.

\section{mRNA and qPCR analysis}

Messenger RNA was extracted as previously described [32]. Quantitative PCR was performed utilizing QuantStudio 7 Real-Time PCR System (Applied Biosystems). Primer sequences used for corresponding genes were (all from $5^{\prime}-3^{\prime}$ ); 185 For GTAACCCGTTGAACCCCATT, Rev CCATCCAATCGGTAG TAGCG; Tbp For TGACTGCAGCAAATCGCTTGG, Rev ACCCTTCACCAATGACT CCTATG; Scd-1 For CAGCCGAGCCTTGTAAGTTC, Rev GCTCTACACCTGCCTCT TCG; Fasn For GGAGGTGGTGATAGCCGGTAT, Rev TGGGTAATCCATAGAGCC CAG; Ppara For GTGGGGAGAGAGGACAGATG, Rev TCCCTGTGAACTGACGTT TG; Pepck For TGTCTTCACTGAGGTGCCAG, Rev CTGGATGAAGTTTGATGCCC; Pgcla For AACCACACCCACAGGATCAGA, Rev TCTTCGCTITATTGCTCCATGA; TNF For GATACGTCAAGCCCCTCAAG, Rev CTGCATCAACGTCTTGGAGA; MCP-1 For TGTCTGGACCCATTCCTTCTTG, Rev AGATGCAGTTAACGCCCCAC; IL-10 For GAAGCATGGCCCAGAAATCA, Rev TGCTCCACTGCCTTGCTCTT; F4/ 80 For CTITGGCTATGGGCTTCCAGTC, Rev GCAAGGAGGACAGAGTTTATCG TG; Cpt1a For AGTGGCCTCACAGACTCCAG, Rev GCCCATGTTGTACAGC TTCC; Acadvl For CTGATGAGCTCCCAGGGTAA, Rev TTGGGCCTCTCTAATACC CA; Acox 1 For CCTGATTCAGCAAGGTAGGG, Rev TCGCAGACCCTGAAGAAA TC; Acad9 For CCGACTAGGCCATCTITTGA, Rev GGAGCTAAAGGGATCTG CAAC; KHK-C For AACTCCTGCACTGTCCTITCCTT, Rev CCACCAGGAAGTCGG CAA; KHK-A For TTGCCGATITTGTCCTGGAT, Rev CCTCGGTCTGAAGGACCA CAT; AldoB For GCTGGGCAATTTCAGAGAGC, Rev GAGGACTCTTCCCC TITGCT; TKFC For CCTTGCTGGGTTAGTAGCCTC, Rev CTITCCCGATA AAACCGGCAT.

\section{Protein extraction and western blot}

Liver samples were homogenized in cell lysis buffer containing protease (Bimake, catalog \#B14002) and phosphatase inhibitors (Bimake, catalog $\# 15002)$, as previously described [32]. Proteins were separated using SDSPAGE and transferred to nitrocellulose membrane (BioRad, catalog \#1620112). Immunoblotting was achieved using the following antibodies from Cell Signaling: phospho-Akt (4060), total Akt (4691), phospho-IGF-I/ IRß (3024), total IR 3 (3025), phospho-Erk1/2 (4370), and total Erk1/2 (9102). The peroxidase-affinipure goat anti-rabbit (111-035-144) and goat antimouse (115-035-003) lgG secondary antibodies were purchased from Jackson ImmunoResearch Laboratories. The vinculin and KHK-C primary antibodies were purchased from Millipore (MAB3574) and Signalway Antibody (21709), respectively. Quantification of immunoblots were performed using ImageJ.

\section{Hepatic function and phenotyping}

Hepatic triglycerides were measured as previously described [5, 33]. For histology, liver tissue was fixed in $10 \%$ buffered formalin, stained with $H \& E$. NAFLD activity score (NAS) was determined from H\&E staining by a certified pathologist [25-27]. 


\section{KHK activity assay}

KHK activity was measured using ADP-Glo kinase assay kit (V6930, Promega). Liver tissues were homogenized in $50 \mathrm{mM}$ HEPES, $\mathrm{pH} 7.4$, $150 \mathrm{mM} \mathrm{KCl}, 4 \mathrm{mM} \mathrm{MgCl} 2,1 \mathrm{mM}$ Glutathione, $1 \mathrm{mM}$ EDTA, $1 \mathrm{mM}$ DT, and $0.05 \%$ CHAPS using Geno/grinder 2010 (SPEX SamplePrep), and centrifuged for $10 \mathrm{~min}$ at $13,000 \mathrm{rpm}$ at $4^{\circ} \mathrm{C}$. The protein supernatant fraction was quantified using the protein BCA assay (Pierce), and KHK activity was measured with $62.5 \mathrm{ng}$ lysate protein after addition of a buffer to $1 \mathrm{mM}$ fructose and $100 \mu \mathrm{M}$ ATP in $50 \mathrm{mM}$ HEPES, pH 7.4, $150 \mathrm{mM} \mathrm{KCl}, 4 \mathrm{mM}$ $\mathrm{MgCl} 2,1 \mathrm{mM}$ Glutathione, and 0.05\% CHAPS. After 1-h incubation, ADP-Glo reagent and kinase detection reagent were added with 40 min interval and luminescence was measured using Synergy $\mathrm{H} 1$ plate reader (BioTek). KHK activity was normalized using non-protein control group and calculated as fold change with wild type control group.

\section{BM transfer}

BM chimeric mice were generated using 8-week-old WT or IL4Ra-deficient donor and recipient mice and mice were conditioned as previously described [27]. Following successful BM reconstitution, mice were placed on chow, $\mathrm{HF}+\mathrm{HC}$ diet as described above.

\section{Mitochondrial isolation and quantification of substrate utilization}

Mitochondria were isolated from intrascapular brown adipose tissue (BAT) and processed and analyzed as previously described [27].

\section{Statistics}

For statistical analysis, choice of test was dependent on number of groups and whether normal distribution exists. For all normally distributed data Unpaired two-tailed Student's $t$ test was used to determine differences between groups. Analysis was performed via GraphPad Prism Software's. Collective indirect calorimetry data was analyzed using analysis of covariance (ANCOVA) with body weight as covariates [34].

\section{Study approval}

All studies were performed in accordance with the procedures outlined in the Guide for the Care and Use of Laboratory Animals and approved by the CCHMC Institutional Animal Care and Use Committee (IACUC).

\section{RESULTS \\ IL-4Ra uncouples glucose metabolism from hepatocellular damage}

Obesity-associated increase in systemic lipopolysaccharide (LPS) levels contributes to low-grade chronic inflammation and obesityassociated metabolic sequelae [35]. IL-4 via IL-4Ra modulates proand anti-inflammatory cytokine production. In vivo LPS challenge of chow diet-fed IL-4Ra-deficient mice, compared to WT controls, drove increased systemic TNF levels and lower IL-10 levels (Supplementary Fig. 1A, B). To correlate the contribution of IL4Ra altered inflammation to obesity we next studied the role of IL4Ra using a well-established mouse model of HF diet-induced obesity [36]. In this setting, HF diet-fed IL-4Ra-deficient mice and WT controls exhibited similar body weight (weight gain and absolute), food intake/caloric intake, systemic leptin levels and white adipose tissue (WAT) depot size (Fig. 1A-F).

We next determined the impact of IL-4Ra on severity of obesityassociated metabolic sequelae. HF diet-fed IL-4Ra-deficient mice, compared to WT controls, had increased fasting glucose and impaired glucose tolerance (Fig. 1G-I). This was independent from variable insulin levels and energy expenditure (Fig. 1J, Supplementary Fig. 2A, B). Insulin signaling involves phosphorylation of various protein kinases (e.g., IR, Akt, Erk1/2) to maintain glucose homeostasis [37]. Basal phosphorylation of IR and AKT in liver, which is driven primarily by circulating insulin levels, was upregulated in HF diet-fed WT mice but not IL-4Ra-deficient mice (Fig. 1K), despite increased basal AKT phosphorylation in IL-4Radeficient mice fed chow diet. HF diet feeding did not impact Erk1/ 2 phosphorylation in either WT or IL-4Ra-deficient mice (Fig. 1K).
Hepatic function and triglyceride (TG) accumulation is linked with dysregulated glucose metabolism, increased circulating free fatty acids and increased hepatic fatty acid synthesis (FAS) due to insulin resistance [38]. HF diet-fed IL-4Ra-deficient mice, compared to WT controls, had similar hepatic TG levels (Fig. 1L). HF diet-fed WT mice showed upregulation of essential genes associated with FAS (e.g., Scd-1, Fasn) compared to low-fat diet-fed counterparts (Supplementary Fig. 3A, B) without altering the expression of FAO genes (e.g., Cpt1a, Acadvl) (Supplementary Fig. 3C, D). Interestingly, in this setting, IL-4Ra-deficient mice did not increase hepatic expression of FAS-associated genes (e.g., Scd-1, Fasn) (Fig. 1N, O). In contrast to HF diet-fed WT mice, IL-4Ra-deficient mice exhibited reduced hepatic expression of FAO-associated genes (e.g., Cpt1a, Acadvl) (Fig. 1P, Q). Further, other important genes in FAO (e.g., Ppara, Pgc1a, Lcad, Acox1) also tended to be decreased in IL-4Radeficient mice (Supplementary Fig. 4A-D). Notably, lack of IL-4Ra expression correlated with mildly reduced hepatocellular damage (Fig. 1M, R). In addition, given the contribution of intestinal inflammation to NAFLD [39], we also examined if the observed effect on obesity-associated sequelae correlated with genotype associated overt intestinal inflammation. Observed effects were independent of genotype associated overt intestinal inflammation (Supplementary Fig. 5). Cumulatively, these findings suggest that IL-4Ra expression uncouples HF diet-associated glucose dysmetabolism from metabolic alterations in the liver.

\section{IL-4Ra regulates carbohydrate diet-driven weight gain and metabolic sequelae}

Consumption of fructose sweetened (high sugar) beverages is considered a key culprit to the obesity pandemic [40]. The role of IL-4Ra in the context of combined high carbohydrate (HC)/ fructose beverages and HF diet feeding has not been examined. In WT mice, combined HF $+\mathrm{HC}$ feeding compared to HF diet alone yielded similar body weight (weight gain and absolute) (Fig. 2A, B), food/caloric intake (Fig. 2C, D) and systemic leptin levels (Supplementary Fig. 6A). In contrast, weight gain of IL-4Radeficient mice was robustly lower under $\mathrm{HF}+\mathrm{HC}$ conditions (Fig. 2A, B), which was in part independent of food/caloric intake (Fig. 2C, D), water/sugar intake (data not shown [DNS]) or leptin production (Supplementary Fig. 6A). As expected, lower weight gain in IL-4Ra-deficient mice correlated with altered WAT distribution and WAT inflammatory gene expression (Supplementary Fig. 6B, C). IL-4Ra-deficient mice, compared to WT mice fed the $\mathrm{HF}+\mathrm{HC}$ diet exhibited slight increase in energy expenditure (EE) at hourly rate (Fig. 2E), increased locomotor activity (Supplementary Fig. 6D, E) but similar respiratory exchange rate (RER) (Fig. 2F). Increase in EE was independent of body weight differences (DNS), while alteration to locomotor activity was dependent on body weight (Supplementary Fig. 6E). BAT mitochondrial oxygen consumption rate (OCR) was not altered in WT or IL-4Ra-deficient mice on HF + HC diet (Supplementary Fig. 6F). In addition, the observed effects were independent of genotype associated overt intestinal inflammation (Supplementary Fig. 7) or altered intestinal expression of a glucose transporter GLUT5 (Supplementary Fig. 8).

We next examined the impact of protection from $\mathrm{HF}+\mathrm{HC}$ dietinduced weight gain on metabolic sequelae. No difference in fasting blood glucose between HF versus HF + HC challenged WT mice was observed. In agreement with lower body weight, IL-4Radeficient mice had lower fasting glucose levels on $\mathrm{HF}+\mathrm{HC}$ diet than on HF diet (Fig. 2G). Further, IL-4Ra-deficient mice, in contrast to WT mice on $\mathrm{HF}+\mathrm{HC}$ diet, showed a slight reduction in liver specific inflammatory gene expression (Supplementary Fig. 9A) improved glucose and insulin tolerance (Fig. $2 \mathrm{H}-\mathrm{J}$ and DNS). In addition, HF $+\mathrm{HC}$ feeding slightly lowered insulin levels in WT mice however such decrease was significantly more pronounced in IL-4Ra-deficient mice. This was consistent with basal insulin levels (Fig. 2J). Phosphorylation of both the insulin receptor 


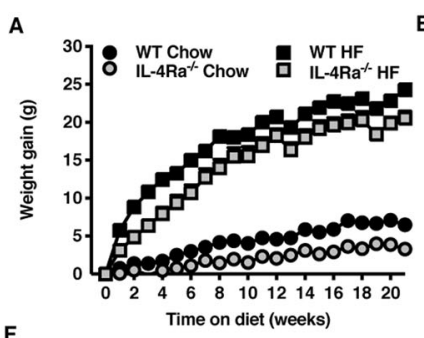

F

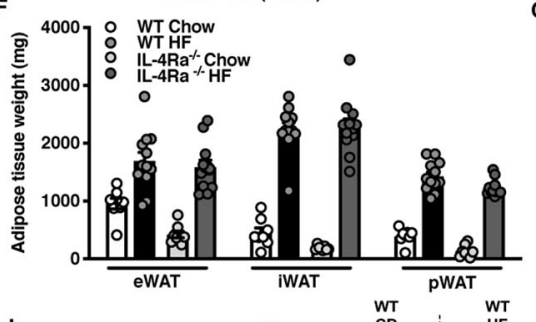

B $\quad$ C

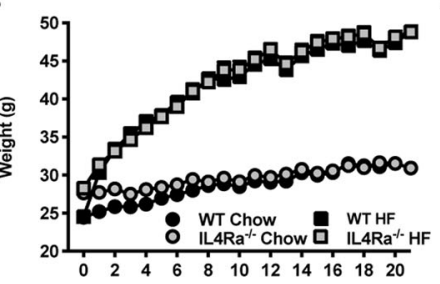

G Time on diet (weeks)

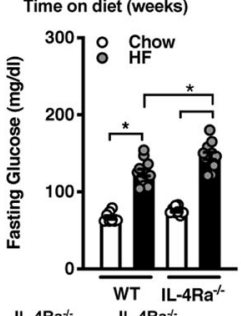

C D

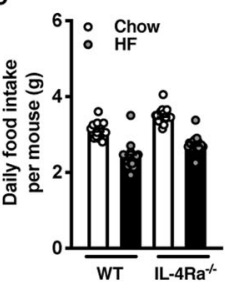

${ }^{H}$

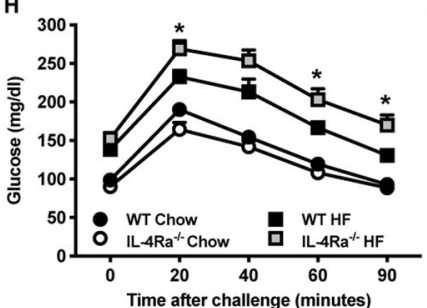

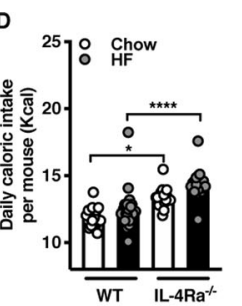

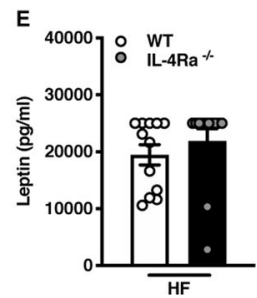

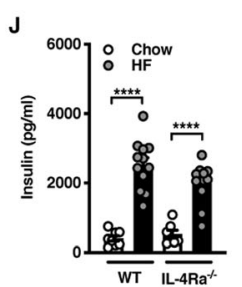

K $\mathrm{IL}-4 \mathrm{Ra}$
$\mathrm{HF}$
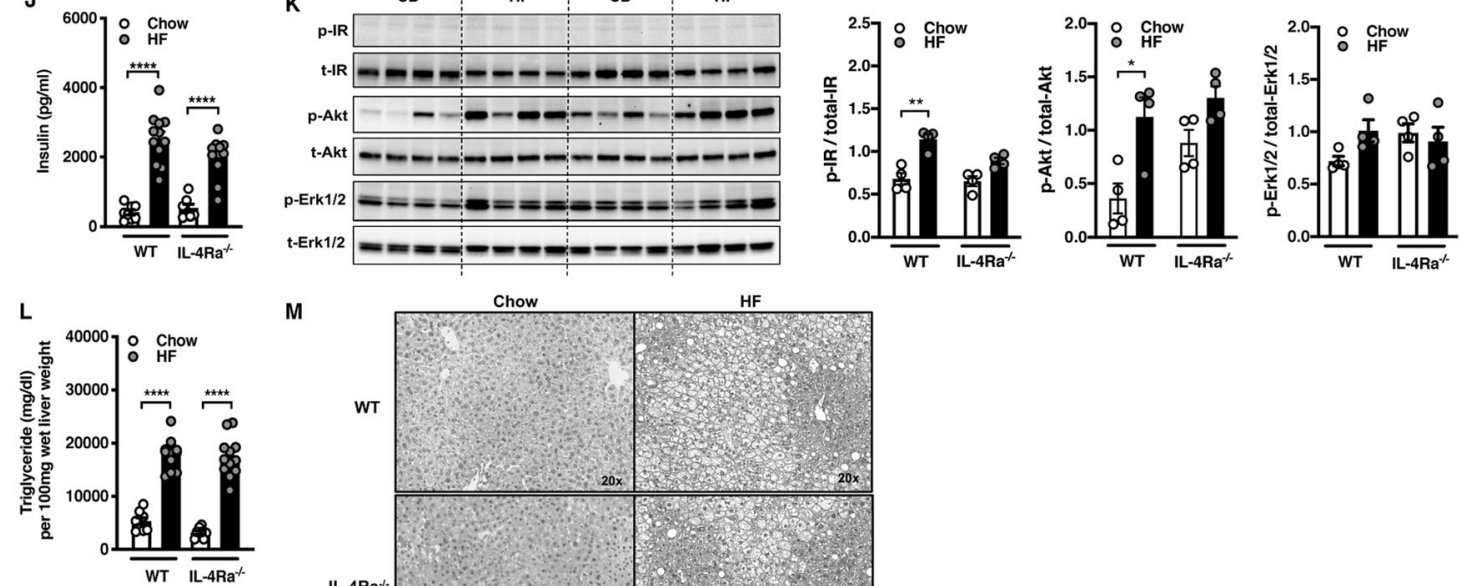

M
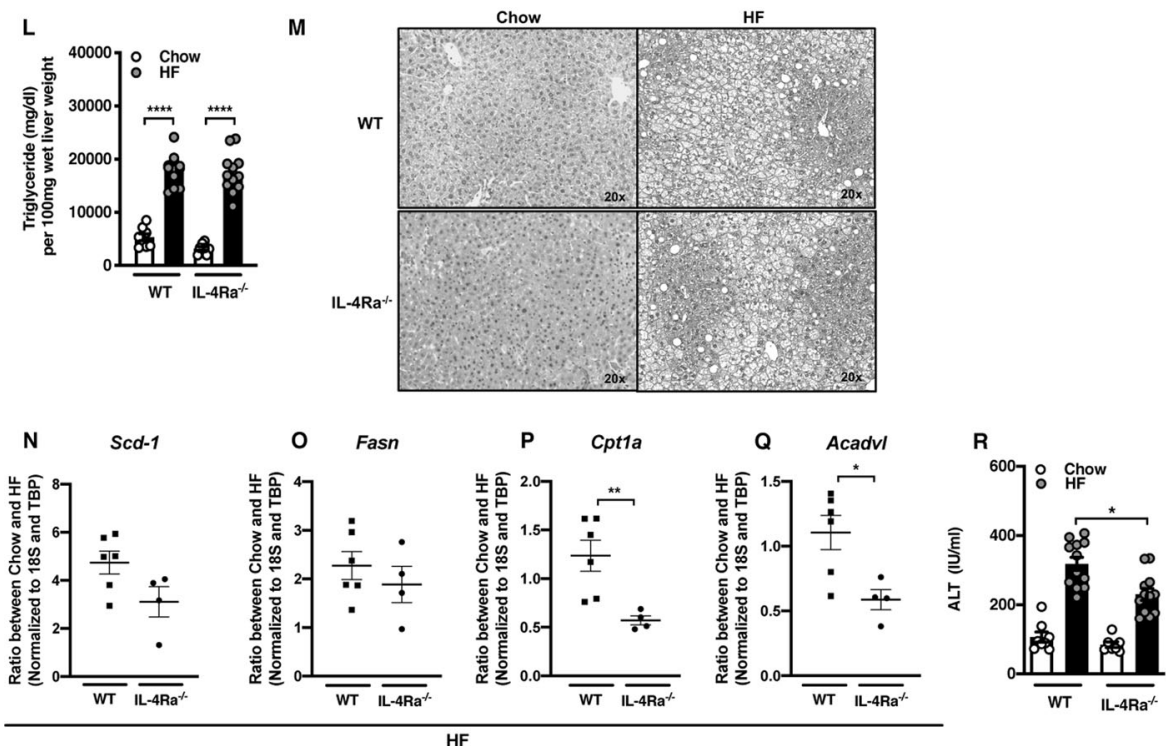

Fig. 1 Dichotomous impact of IL-4Ra expression on HF diet-induced metabolic sequelae. WT and IL-4R $\alpha^{-1-}$ mice were fed a chow or highfat (HF) diet for 22 weeks. A Total body weight gain over time. B Absolute body weight over time. C Daily food intake per mouse. D Daily caloric intake per mouse. E Systemic leptin concentrations at time of harvest. F White adipose tissue (WAT) weight at time of harvest. eWAT epidydimal WAT, iWAT inguinal WAT, pWAT perirenal WAT. G Serum fasting glucose levels at 12 weeks of dietary challenge. H Glucose tolerance test at 12 weeks of dietary challenge. I Area under the curve (AUC) of glucose tolerance test at 12 weeks of dietary challenge. J Fasting serum insulin concentrations at time of harvest. K Liver IR, Akt, Erk1/2 levels at time of harvest as determined by western blot. $\mathbf{L}$ Liver triglycerides at time of harvest. $\mathbf{M}$ Representative histology images (H\&E staining). $\mathbf{N}, \mathbf{O}$ Ratios of fatty acid synthesis gene expression in the liver of mice fed HF diet at time of harvest. P, Q Ratios of Fatty acid oxidation gene expression in the liver of mice fed HF diet at time of harvest. R Systemic alanine transaminase (ALT) levels at time of harvest. A-F Representative of 2 independent experiments, $n=12 /$ condition. I, $\mathbf{J}$ Representative of 2 independent experiments, $n=8-12 /$ condition. K A single experiment of $n=4 /$ condition. L Representative of 2 independent experiments, $n=8-12 /$ condition. M Representative of 2 independent experiments of, $n=8-12 /$ condition. $\mathbf{N}-\mathbf{Q}$ A single experiment, $n=4 /$ condition. R Representative of 2 independent experiments, $n=8-12$ /condition. In bar graphs and line graphs data represents mean \pm SEM. A, B, N-Q Unpaired two-tailed Student's $t$ test. ${ }^{*} P<0.05$, ${ }^{* *} P<0.01,{ }^{* * *} P<0.001,{ }^{* * * *} P<0.0001$. H Area under the curve (AUC). C-G, I-L, $\mathbf{R}$ One-way ANOVA followed by multiple comparisons. ${ }^{*} P<0.05$, ${ }^{* *} P<0.01$, ${ }^{* *} P<0.001$.

(Fig. 2K) and Akt serine 473 was reduced in context of $\mathrm{HF}+\mathrm{HC}$ feeding in both genotypes (Fig. 2K). HF $+\mathrm{HC}$ diet feeding did not impact Erk1/2 phosphorylation in either WT or IL-4Ra-deficient mice (Fig. 2K). A role of insulin signaling in the liver is to suppress gluconeogenic enzymes via modulation of FoxO1. PEPCK gene expression was elevated in $\mathrm{HF}+\mathrm{HC}$-fed IL-4Ra-deficient mice (Fig. 2L), consistent with lower basal insulin levels and Akt signaling in these mice. 

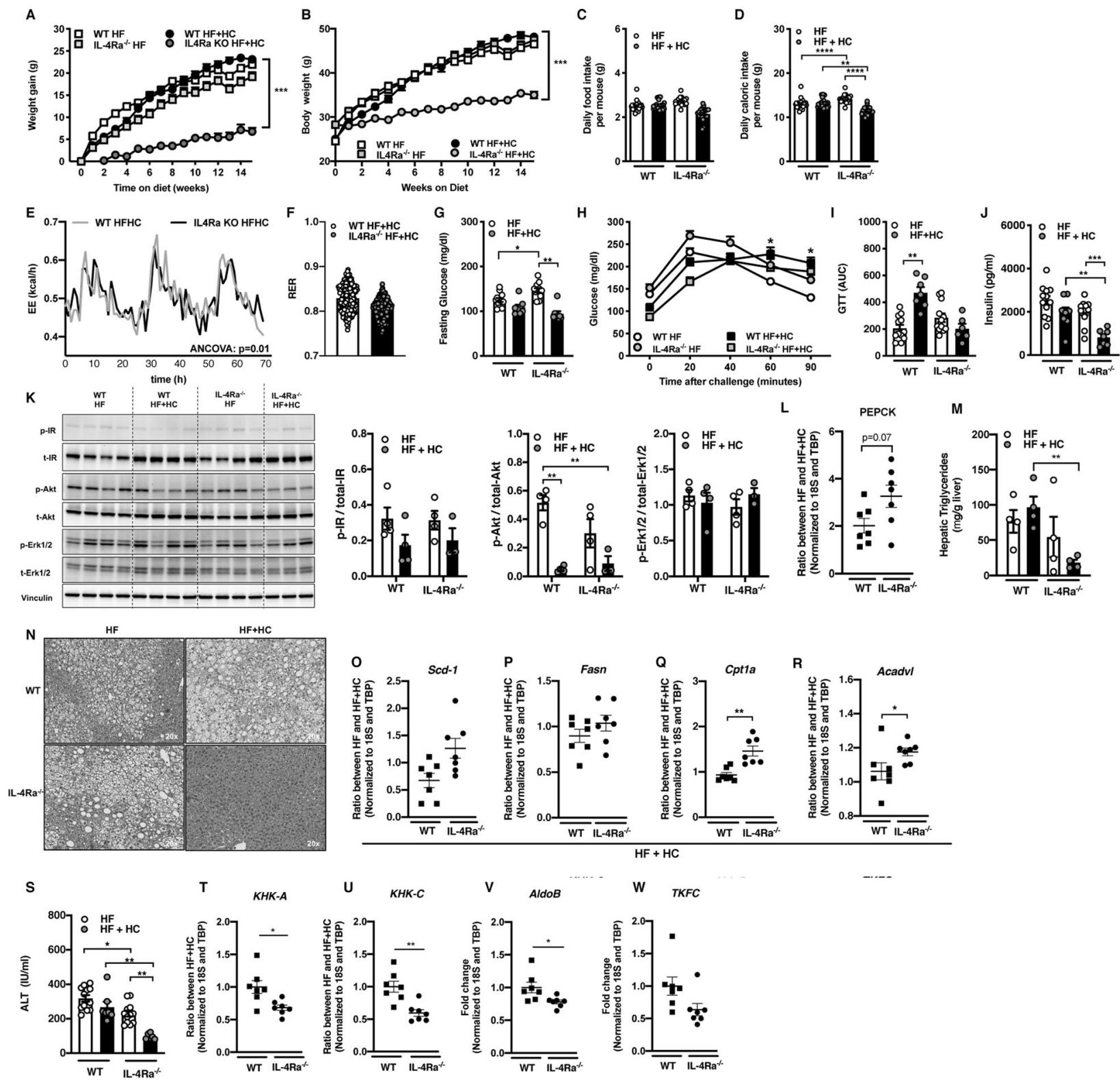

Fig. 2 IL-4Ra regulates HF + HC diet-induced weight-gain and associated metabolic sequelae. WT and IL-4R $\alpha^{-/-}$mice were fed a HF diet plus supplementation of fructose ( $\mathrm{HF}+\mathrm{HC}$ ) for 16 weeks. A Total body weight gain over time. B Absolute body weight over time. C Daily food intake per mouse. D Daily caloric intake per mouse. E Energy expenditure (EE) in HF + HC at 6 weeks of dietary challenge. F Respiratory exchange rate (RER) at 6 weeks of dietary challenge. G Serum fasting glucose levels at 12 weeks of dietary challenge. $\mathbf{H}$ Glucose tolerance test over time at 12 weeks of dietary challenge. I AUC of glucose tolerance test at 12 weeks of dietary challenge. J Fasting insulin concentrations at time of harvest. K Liver IR, Akt, Erk1/2 levels at time of harvest as determined by western blot. L PEPCK gene expression in liver at time of harvest. $\mathbf{M}, \mathbf{N}$ Liver triglycerides at time of harvest and representative histology images (H\&E staining). $\mathbf{O}, \mathbf{P}$ Fatty acid synthesis gene expression at time of harvest. Q, R Fatty acid oxidation gene expression at time of harvest. S Systemic alanine transaminase (ALT) levels at time of harvest. T, $\mathbf{U}$ KHK-A and KHK-C expression in liver at time of harvest. $\mathbf{V}, \mathbf{W}$ AldoB and TKFC expression in liver at time of harvest. O-R, T-W Gene expression at time of harvest. A-D Representative of 2 independent experiments, $n=12 /$ condition. $\mathbf{E}$, $\mathbf{F}$ A single experiment $n=4 /$ condition. G-J Representative of 2 independent experiments, $n=8-12 /$ condition. K-N, O-R A single experiment $n=3-4 /$ condition. $\mathbf{S}$ Representative of 2 independent experiments $n=8-12 /$ condition. T-W A single experiment $n=6 / 7$ condition. In bar graphs and line graphs data represents mean \pm SEM. A, B, H Area under the curve (AUC). C, D, G, I-M, S One-way ANOVA followed by multiple comparisons. ${ }^{*} P<0.05$, ${ }^{* *} P<0.01,{ }^{* * *} P<0.001$. D, E Analysis of covariance (ANCOVA) with body weight as covariate. ${ }^{*} p<0.05,{ }^{* * *} p<0.001$. O-R, T-W Unpaired twotailed Student's $t$ test. ${ }^{*} P<0.05,{ }^{* *} P<0.01,{ }^{* * *} P<0.001,{ }^{* * * *} P<0.0001$.

Protection from weight gain and improved glucose handling in IL-4Ra-deficient mice fed HF + HC diet, compared to WT controls, correlated with decreased hepatic steatosis (Fig. 2M, $\mathrm{N})$. Improved liver TG deposition was independent of altered expression of FAS-associated genes (e.g., Scd-1 and Fasn) (Fig. 2O, P), whereas the expression of FAO genes (e.g., Cpt1a,
Acadvl, Pgc1a, Acad9) was increased in IL-4Ra-deficient mice, compared to WT controls (Fig. 2Q, R and Supplementary Fig. 9B, C). In line with reduced hepatic TG levels (Fig. 2M) and increased FAO, IL-4Ra-deficient mice, compared to WT controls, were protected from $\mathrm{HF}+\mathrm{HC}$ diet-driven hepatocellular damage (Fig. 2S). 

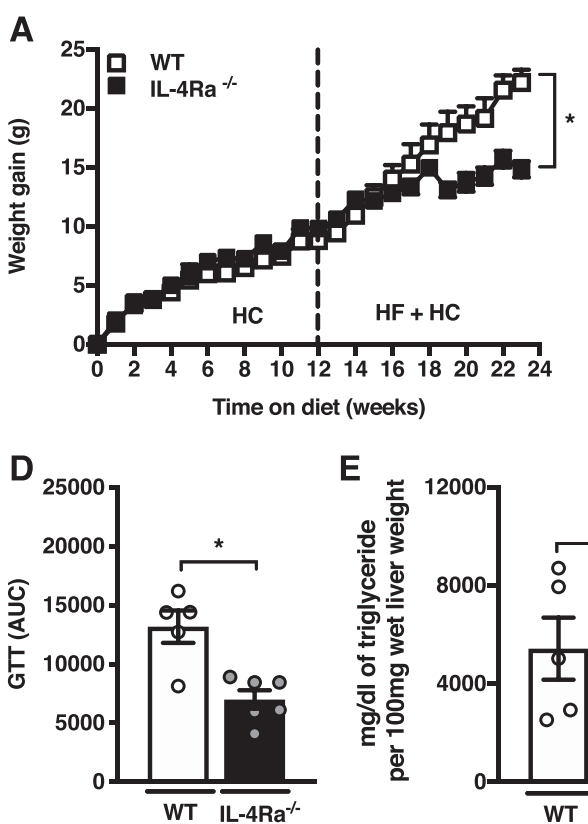
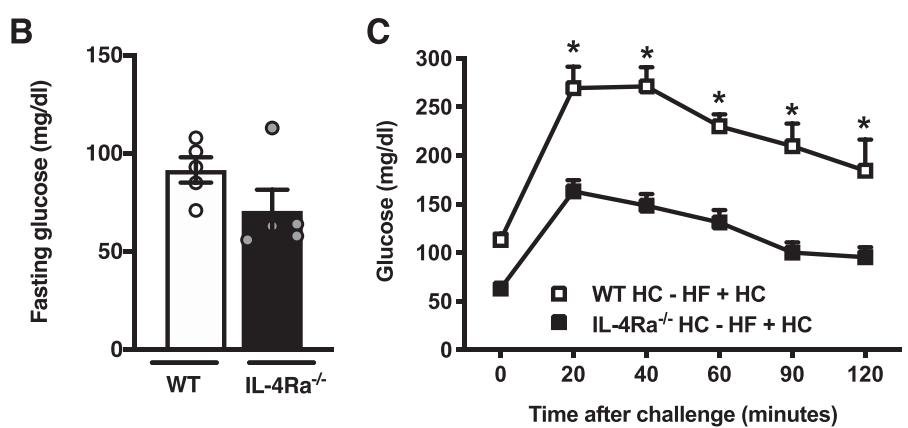
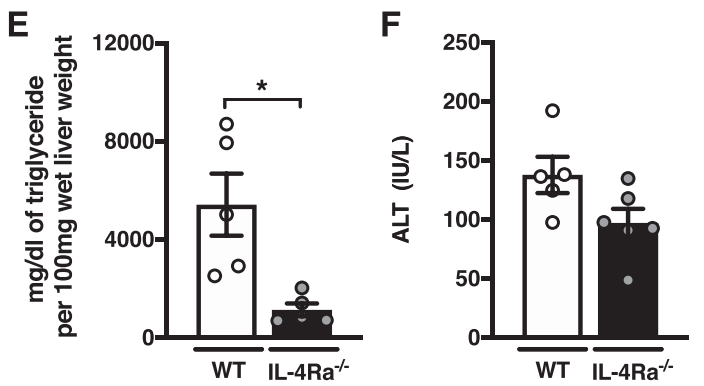

Fig. 3 IL-4Ra weight gain-associated sequelae are dependent on the presence of combined high carbohydrate and high-fat diet feeding. WT and IL-4R $\alpha^{-1-}$ mice were fed a HC diet for 12 weeks and were subsequently switched to a HF or HF $+\mathrm{HC}$ diet for an additional of 12 weeks (24 weeks in total). A Total body weight gain over time. B Serum fasting glucose levels at week 12 of dietary challenge. C Glucose tolerance test at 12 weeks of dietary challenge. D Area under the curve (AUC) of glucose tolerance test at 12 weeks of dietary challenge. E Liver triglycerides at time of harvest. F Systemic alanine transaminase (ALT) levels at time of harvest. A-F Representative of 2 independent experiments, $n=5-6 /$ condition. In bar graphs and line graphs data represents mean \pm SEM. A Unpaired two-tailed Student's $t$ test. ${ }^{*} P<0.05$, ${ }^{* *} P<0.01,{ }^{* * *} P<0.001,{ }^{* * *} P<0.0001$. C, D Area under the curve (AUC). B, E, F One-way ANOVA followed by multiple comparisons. ${ }^{*} P<0.05$, $* * P<0.01, * * * P<0.001$.

Ketohexokinase (KHK) mediates both fructose-induced de novo lipogenesis (DNL) and suppression of FAO [5, 32]. Total $\mathrm{KHK}$ is primarily composed of KHK-A (ubiquitously expressed) and KHK-C (primarily expressed in liver, kidney, intestine) subunits. KHK-C exhibits greater affinity for fructose and is expressed $\sim 400 \mathrm{x}$ more than KHK-A in the liver (Supplementary Fig. 9D). There was a trend towards reduced expression (Fig. 2T, $\mathrm{U})$ and activity of KHK in IL-4Ra-deficient mice fed HF + HC diet compared to WT controls (Supplementary Fig. 9D-G). Further, other enzymes in fructose metabolism (e.g., AldoB, TFKC) were reduced in IL-4Ra-deficient mice fed $\mathrm{HF}+\mathrm{HC}$ diet compared to WT controls (Fig. 2V, W). These data suggest an overall reduced ability to metabolize fructose, and may potentially contribute to lower weight gain and improved liver TG handling. Together, our data suggest that lack of IL-4Ra is associated with a trend towards decreased KHK-C expression and increased FAO upon $\mathrm{HF}+\mathrm{HC}$ diet feeding. Even though $\mathrm{HF}+\mathrm{HC}$ diet increased overall KHK-activity, reduced KHK-C expression potentially yields lower overall KHK activity in IL-4Ra-deficient mice contributing to metabolic improvements.

\section{Combination of high carbohydrate with high-fat diet is required for weight gain-associated phenotypes in IL-4Ra- deficient mice}

To determine whether IL-4Ra-associated phenotypic changes were dependent on a HF $+\mathrm{HC}$ diet, WT and IL-4Ra-deficient mice were first fed $\mathrm{HC}$ diet alone and subsequently switched to a HF + $\mathrm{HC}$ diet. Initial exposure to HC did not impact IL-4Ra-dependent modulation of weight gain. Following the diet switch to $\mathrm{HF}+\mathrm{HC}$, IL-4Ra-deficient mice were protected from continuous weight gain as compared to WT mice (Fig. 3A). Decreases in weight gain correlated with reduced adiposity, total fat and lean mass (Supplementary Fig. 10A-C) in IL-4Ra-deficient mice fed a $\mathrm{HF}+\mathrm{HC}$ diet. Fasting blood glucose was slightly decreased in
IL4-Ra-deficient mice compared to WT mice, switched to HF + HC diet (Fig. 3B). In agreement with these results, glucose sensitivity was better maintained in IL-4Ra-deficient mice as shown by glucose tolerance testing, compared to WT controls (Fig. 3C, D). The combination of $\mathrm{HF}+\mathrm{HC}$ feeding also resulted in reduced hepatic TG accumulation and trend towards lower hepatocellular damage in IL-4Ra-deficient mice (Fig. 3E, F). Together, these findings support the importance of IL-4Ra signaling in combined $\mathrm{HF}+\mathrm{HC}$ diet-induced metabolic sequelae.

\section{Non-hematopoietic IL-4Ra may contribute obesity and obesity-associated sequelae}

IL-4Ra is expressed by various cell types including immune cells, endothelial cells, adipocytes and hepatocytes [41]. As fructose is processed by the liver, we next examined if hematopoietic or non-hematopoietic IL-4Ra was required for modulation of $\mathrm{HF}+$ $\mathrm{HC}$ diet dependent phenotypes. Reciprocal bone marrow transfers between WT and IL-4Ra-deficient (Fig. 4A) potentially suggested that non-hematopoietic (WT BM to IL-4Ra-deficient mice transfer) locus of IL-4Ra expression was in part responsible for the $\mathrm{HF}+\mathrm{HC}$ diet-driven weight gain (Fig. 4B) and altered adiposity (Supplementary Fig. $11 \mathrm{~A}-\mathrm{C}$ ). The hematopoietic component (BM from WT) which now included IL-4R expression on the hematopoietic cells in IL-4Ra-deficient mice was not sufficient to alter weight gain. In addition, the transfer of IL-4Ra-deficient $\mathrm{BM}$ to WT mice did not protect from HF + HC-driven weight gain. Non-hematopoietic IL-4Ra was also involved in regulation of glucose metabolism (Fig. 4C, D). Similarly, hepatic TG accumulation was reduced in mice lacking IL-4Ra expression in nonhematopoietic compartment but no differences were observed in hepatocellular damage (Fig. 4E, F). Together, these findings may invoke the important role of non-hematopoietic locus of IL-4Ra expression as a modulator of $\mathrm{HF}+\mathrm{HC}$ diet-driven weight gain and obesity-associated sequelae. 


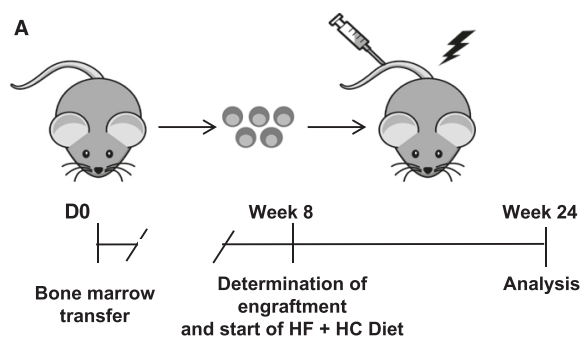

B

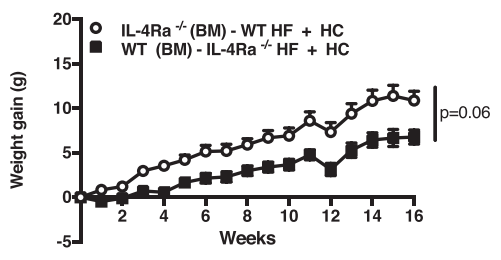

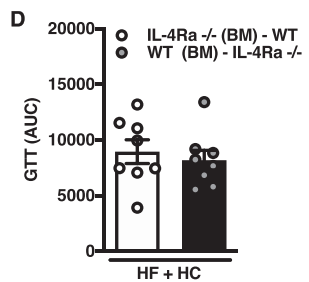

E

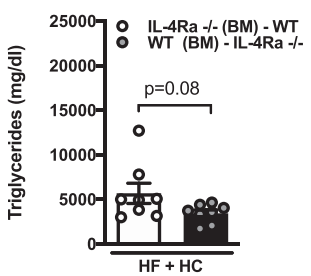

$\mathbf{F}$

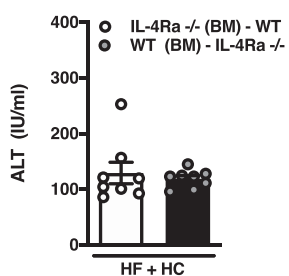

Fig. 4 Non-hematopoietic IL-4Ra expression impacts HF + HC induced weight gain and associated sequelae. Reciprocal bone marrow transfers (BMT) between WT and IL-4R $\alpha^{-1-}$ mice were performed and success of bone marrow reconstitution was confirmed at 8 weeks posttransfer. Successfully transferred mice were subsequently placed on HF + HC diet for 16 weeks. A Schematic overview of BMT experimental setup. B Total body weight gain over time. C Serum fasting glucose levels at 12 weeks of dietary challenge. D Area under the curve (AUC) of glucose tolerance test at 12 weeks of dietary challenge. E Liver triglycerides at time of harvest. F Systemic alanine transaminase (ALT) levels at time of harvest. B-E One independent experiment, $n=7-8 /$ condition. In bar graphs and line graphs data represents mean \pm SEM. B-F Unpaired two-tailed Student's $t$ test. ${ }^{*} P<0.05,{ }^{* *} P<0.01,{ }^{* * *} P<0.001,{ }^{* * * *} P<0.0001$.

\section{Non canonical IL-4Ra contributes to obesity and metabolic sequelae}

Canonical signaling downstream of IL-4Ra involves STAT6 phosphorylation and induction of various (inflammatory) mediators. IL-4 dependent activation of STAT6 signaling modulates glucose energy metabolism in hematopoietic cells [42]. However, unlike IL-4Ra-deficient mice fed HF + HC diet, STAT6-deficient mice on $\mathrm{HF}+\mathrm{HC}$ diet were not protected from weight gain (Fig. 5A) and exhibited similar adiposity (Fig. 5B). Further, both WT and STAT6-deficient mice exhibited similar fasting glucose, glucose tolerance (Fig. 5C, D, E), hepatic TG accumulation and hepatocellular damage (Fig. 5F, G). Together, these data suggest that canonical STAT6 signaling is not required to propagate the phenotypes observed in IL-4Ra-deficient mice on $\mathrm{HF}+\mathrm{HC}$ diet.

\section{DISCUSSION}

The contribution of excessive fructose intake to the growing obesity pandemic and associated pathogenesis of metabolic sequelae remains controversial [43, 44]. Fructose metabolism modulates inflammatory responses and organ and tissue functions [45]. Altered immune responsiveness is a critical causative link between obesity and pathogenesis of obesity-associated diseases. Obesity favors systemic endotoxemia (LPS levels) and systemic inflammation shapes glucose and insulin metabolism [46]. IL-4Ra-deficient mice challenged with LPS exhibited increased proinflammatory cytokine production, invoking the potential role for IL-4Ra-driven regulation of immune responses in glucose metabolism. We show that despite similar degrees of adiposity, IL-4Ra expression uncoupled glucose metabolism from hepatocellular damage in HF diet-fed mice (e.g., reduced hepatocellular damage despite worse glucose dysmetabolism). IL4 inhibits hepatic expression of PPARa blocking fatty acid betaoxidation and shifting the metabolic reliance of hepatocytes to glucose oxidation [20]. Downstream catabolic activity of PPARa promotes hepatic and WAT triglyceride oxidation [47]. Given that hepatic PPARa expression was maintained in HF-diet-fed IL-4Radeficient mice, these findings could explain the increased hepatic TG accumulation and glucose dysmetabolism but attenuated hepatocellular damage.

In contrast to HF diet feeding, the effect of the IL-4Ra/IL-4/ STAT6 axis in combination of $\mathrm{HF}+\mathrm{HC}$ feeding have not been studied. Combined HF $+\mathrm{HC}$ feeding resulted in robust protection from weight gain and weight-associated metabolic derangements in IL-4Ra-dependent manner. Tissue specific inflammatory markers in adipose tissue and liver seemed to be reduced in IL-4Radeficient mice compared to WT mice on HF + HC dietary challenge. Dietary challenge-induced systemic and tissue inflammation is associated with increased metabolic sequelae. A reduction in inflammatory markers potentially plays a role in the protection from weight-gain and weight-associated derangements. Published reports suggest that IL-4Ra expression regulates pre-adipocyte differentiation, invoking the possibility of divergent impact of IL-4 on white and brown adipose tissue. AT is a key component to energy expenditure (EE), which in turn regulates body weight. IL-4Ra modified HF + HC-driven EE independent of body weight (Fig. 2E). As the IL-4Ra is a shared receptor for IL-4 and IL-13, altered IL-13 levels in obesity might also play a role. However, HF + HC feeding did not amplify systemic IL-13 levels (data not shown) while IL-4Ra-deficient mice exhibited reduced IL13 levels (data not shown). Future studies investigating tissue/cell type specific deletion of IL-4Ra in context of HF $+\mathrm{HC}$ diet-driven 

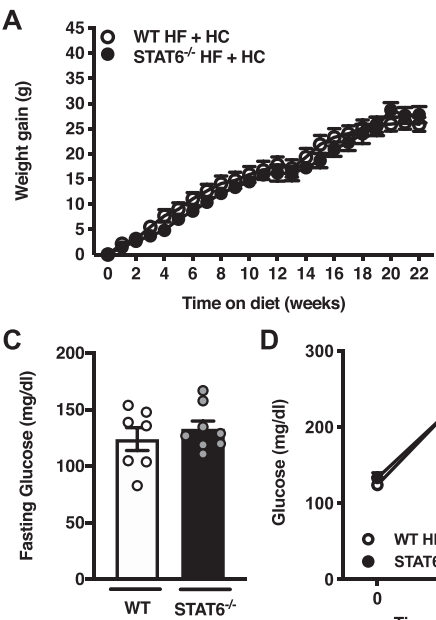$$
\text { D }
$$

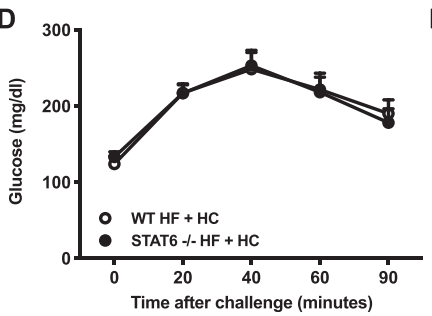

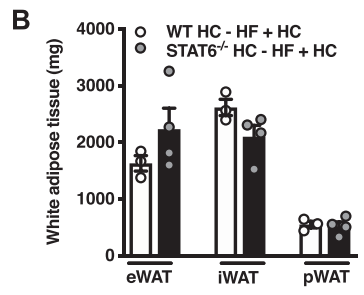
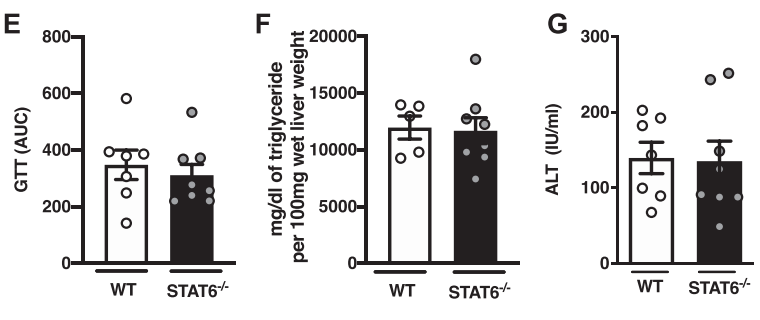

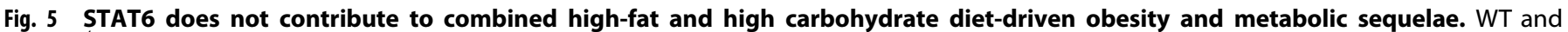

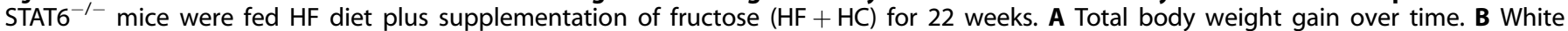

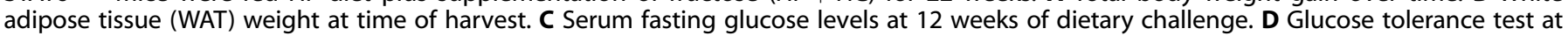

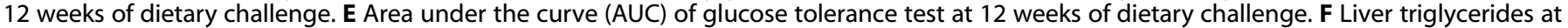

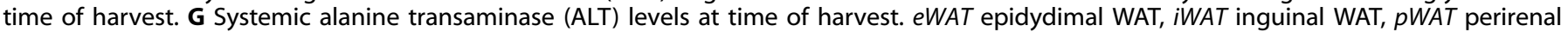

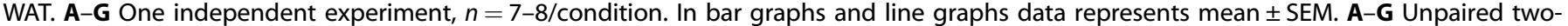
tailed Student's $t$ test. ${ }^{*} P<0.05,{ }^{* *} P<0.01,{ }^{* * *} P<0.001,{ }^{* * * *} P<0.0001$.

obesity, EE, and metabolic disease are warranted. Analysis of weight matched WT and IL-4Ra groups in context of HF $+\mathrm{HC}$ would be central to defining the role of weight gain on the IL-4Radependent metabolic sequelae phenotypes.

Increased hepatic FAO is another mechanism known to regulate weight gain and metabolic derangements [48]. Our data showed upregulated hepatic expression FAO-associated genes in IL-4Radeficient mice compared to WT mice fed HF + HC diet. We also showed that $\mathrm{HC}$ feeding alone was not sufficient to impact weight gain. A switch to a combined $\mathrm{HF}+\mathrm{HC}$ diet feeding precluded weight gain in IL-4Ra-deficient mice invoking the possibility that IL-4Ra unlocks a fundamental functional convergence between cellular metabolism and processing of $\mathrm{HF}+\mathrm{HC}$ diet. Together, these findings amplify the complexity of the IL-4 axis in modulation of obesity and highlight the possibility that observed divergent effects may be dietary substrate driven.

Fructose metabolism primarily takes place in the intestine and liver. Hepatic fructolysis by KHK is associated with high fructose intake-driven weight gain, adiposity, insulin resistance, hyperlipidemia, and DNL [49]. DNL is driven by fructose-mediated insulin signaling independent activation of SREBP-1 and ChREBP-driven lipogenesis [50]. IL-4Ra-deficient mice on $\mathrm{HF}+\mathrm{HC}$ diet showed improved glucose tolerance and had reduced glucose and insulin levels compared to WT controls. Non-stimulated basal phosphorylation of Akt at serine 473 is driven by circulating insulin levels. Consistent with lower insulin levels, Akt phosphorylation at serine 473 (S473), which impacts protein kinase activity of Akt [51], was lower in IL-4Ra-deficient mice with $\mathrm{HF}+\mathrm{HC}$ feeding. A role of Akt activation in the liver is to phosphorylate FoxO1, subsequently removing it from the nucleus to lower gluconeognic gene expression. The observed increase in hepatic phosphoenolpyruvate carboxykinase (PEPCK; Fig. 2L) expression in IL-4Ra-deficient mice fed $\mathrm{HF}$ and $\mathrm{HF}+\mathrm{HC}$ diets thus correlates with a decrease in pAkt levels in these mice. Existing literature shows that IL-4Ra recruits the insulin receptor substrate-2 (IRS-2) to associate with PI3K, impacting glucose metabolism that could drive observed differences in insulin signaling in WT versus IL-4Ra-deficient mice [52].

Fructose promotes hepatic steatosis through a variety of mechanisms, including promoting DNL and impairing hepatic FAO [53]. In fact, fructose impairs FAO compared to glucose, whereas KHK knockdown in liver increases FAO gene expression [32]. IL-4Ra-deficient mice fed HF $+\mathrm{HC}$ diet exhibited a trend towards decreased protein expression of KHK-C. This suggests that IL-4Ra-deficient mice are not able to sufficiently metabolize fructose in their liver, which could contribute to decreased weight gain, improved steatosis and better glucose tolerance. In addition, a decrease in liver KHK-C expression correlated with a concomitant increase in the expression of FAO-associated genes compared to WT mice in line with our previous result that knockdown of KHK increased hepatic FAO [32]. Thus, potential IL-4Ra-driven regulation of KHK-C and hepatic FAO could in part explain the reduced hepatic TG levels and hepatocellular damage.

Aside from immune cells, various non-hematopoietic cells and tissues express IL-4Ra. We show that non-hematopoietic expression of IL-4Ra potentially contributed to the protective phenotype observed upon HF + HC diet feeding. Transfers of WT bone marrow into IL-4Ra-deficient recipient mice yielded reduced weight gain, adiposity, fasting glucose levels, hepatic TG levels, and hepatocellular damage. Expression of IL-4Ra in nonhematopoietic cells contributed to other diseases including asthma, cancer, and hepatitis [54, 55]. IL-4Ra drives hepatic apoptosis, myofibroblast differentiation, and pre-adipocyte differentiation. Thus, alterations in non-hematopoietic IL-4Ra expression may impact hepatocellular damage, hepatic fibrosis, and adipocyte differentiation and function. Future studies fully warrant the investigation of tissue specific differences in nonhematopoietic IL-4Ra expression and their contribution to HFand $\mathrm{HF}+\mathrm{HC}$ diet-induced obesity.

Activation of STAT6 impacts cell polarization and differentiation and regulates immune responses [56]. IL-4 and IL-13 are two main drivers of STAT6 activation. Where the contribution of STAT6 in HF diet feeding has been demonstrated [20] the role of STAT6 in HF + HC diet feeding remained undefined. Unlike the observed protection from weight gain in IL-4Ra-deficient mice on $\mathrm{HF}+\mathrm{HC}$ diet, STAT6 KO mice on HF + HC diet were not protected from weight gain, adiposity, glucose dysmetabolism, or hepatocellular damage. Importantly, tissue specific differences in STAT6 expression between the liver, skeletal muscle, and AT could contribute to observed differences in metabolic derangements [57]. As a number of non-canonical pathways can drive IL-4 mediated effects [58] our 


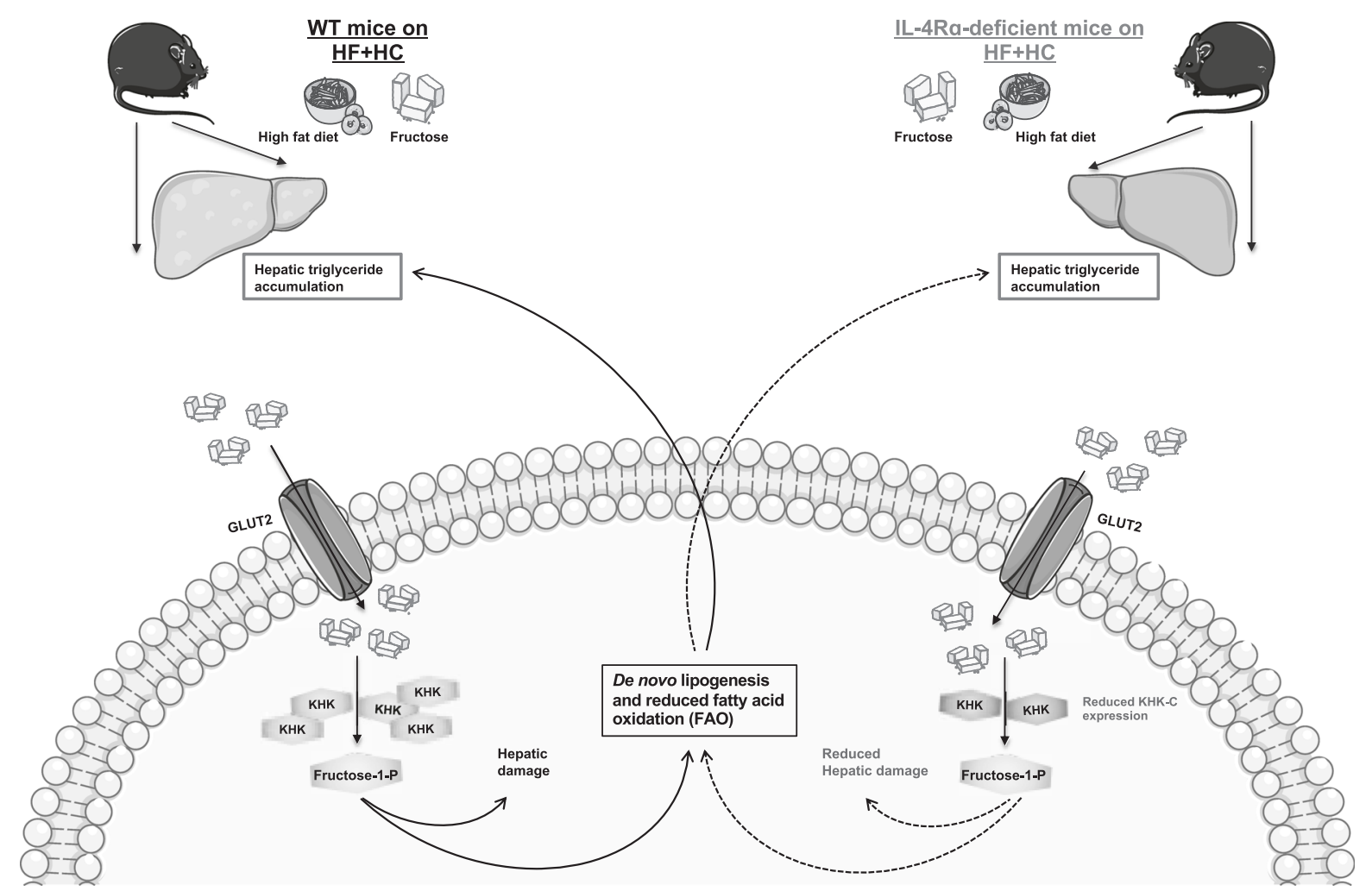

Fig. 6 Schematic overview of potential IL-4Ra contribution to HF + HC-driven obesity and obesity-associated metabolic derangements. Schematic overview of the potentially impact of IL-4R $\alpha$-deficiency on hepatic fructose metabolism in mice fed high-fat + high carbohydrate diet. IL-4R $\alpha$-deficient mice on HF + HC diet show protection from weight gain, adiposity, insulin dysmetabolism and hepatocellular damage. Fructose is metabolized in the intestine and the liver. KHK-C is the first/key enzyme in fructolysis. KHK-C impacts de novo lipogenesis (DNL) and suppress fatty acid oxidation (FAO). Our data shows that IL-4R $\alpha$-deficient mice potentially have lower KHK-C expression which can explain their increased expression of genes related to FAO and could represent an underlying mechanism explaining their protection from weight gain and associated metabolic derangements.

data also suggest that activation of a non-canonical pathway (e.g., Notch, mTOR) $[59,60]$ downstream of IL-4Ra may be responsible for observed phenotypes. The contribution of these pathways to HF and $\mathrm{HF}+\mathrm{HC}$ induced obesity is warranted.

In sum, our report highlights an undervalued role for IL-4Ra signaling in the context of high fructose-driven obesity suggesting that greater examination of this signaling pathway could lead to novel insights into disease pathogenesis (Fig. 6). Thus, it is plausible that novel pharmacological intervention in the IL-4/IL4Ra axis function, in both hematopoietic as well as non-hematopoietic cells, would provide novel approaches to dampen high dietary fructose-driven metabolic harm associated with obesity.

\section{Study limitations}

Our new insights demonstrating the impact of IL-4Ra expression to high fructose-driven obesity development provide the opportunity for greater examination of IL-4 axis and the downstream linked non-canonical pathways to high-fat + high carbohydrate dietsassociated metabolic disease pathogenesis. Our study however still leaves several questions unanswered. Specifically, future mechanistic interrogations of the pathways/signaling cascades underlying IL-4Ra expression importance in this setting are needed. Our studies also have not examined whether the observed effects are gender specific given previous reports invoking the importance of thermoneutral housing and hormonal imbalance on HF diet-driven metabolic sequelae in female mice. Additionally, future studies should focus on analysis of weight matched WT and IL-4Ra ${ }^{-1-}$ mice- findings central for uncovering the impact of weight difference on metabolic disease severity in this system. We also did not examine the impact of tissue specific deletion of IL-4Ra or STAT6 expression and whether specific tissues/cell types could dichotomously impact inflammatory/anti-inflammatory responses in this setting and thus shape metabolic sequelae. Lastly, our study did not exploit potential differences in systemic inflammatory phenotypes and immune cell development and function between the HF and HF + HC-fed groups. Recent studies have shown that proinflammatory mediators may regulate metabolic sequelae [61]. Further, specific hepatic inflammatory Th17 cells specifically contribute to obesity induced liver damage [62]. Combined future investigations in these areas will be critical to pinpoint the interplay of immune cells and tissue non-hematopoietic cells utilizing IL-4Radependent signaling in the setting of $\mathrm{HF}$ versus $\mathrm{HF}+\mathrm{HC}$ diet exposure and the relevance of such biological processes to obesitydriven metabolic disease progression.

\section{REFERENCES}

1. Finucane MM, Stevens GA, Cowan MJ, Danaei G, Lin JK, Paciorek CJ.Global Burden of Metabolic Risk Factors of Chronic Diseases Collaborating Group (Body Mass Index) et al. National, regional, and global trends in body-mass index since 1980: systematic analysis of health examination surveys and epidemiological studies with 960 country-years and 9.1 million participants. Lancet. 2011;377:557-67. 
2. Charrez B, Qiao L, Hebbard L. The role of fructose in metabolism and cancer. Horm Mol Biol Clin Investig. 2015;22:79-89.

3. Softic S, Cohen DE, Kahn CR. Role of dietary fructose and hepatic de novo lipogenesis in fatty liver disease. Dig Dis Sci. 2016;61:1282-93.

4. Softic S, Stanhope KL, Boucher J, Divanovic S, Lanaspa MA, Johnson RJ, et al. Fructose and hepatic insulin resistance. Crit Rev Clin Lab Sci. 2020;57:308-22.

5. Softic S, Gupta MK, Wang GX, Fujisaka S, O'Neill BT, Rao TN, et al. Divergent effects of glucose and fructose on hepatic lipogenesis and insulin signaling. J Clin Invest. 2017; 127:4059-74.

6. Cioffi F, Senese R, Lasala P, Ziello A, Mazzoli A, Crescenzo R, et al. Fructose-rich diet affects mitochondrial DNA damage and repair in rats. Nutrients. 2017;9:4.

7. Giles DA, Moreno-Fernandez ME, Divanovic S. IL-17 axis driven inflammation in non-alcoholic fatty liver disease progression. Curr Drug Targets. 2015;16:1315-23.

8. Braunersreuther V, Viviani GL, Mach F, Montecucco F. Role of cytokines and chemokines in non-alcoholic fatty liver disease. World J Gastroenterol. 2012;18:727-35.

9. Luzina IG, Keegan AD, Heller NM, Rook GA, Shea-Donohue T, Atamas SP. Regulation of inflammation by interleukin-4: a review of "alternatives". J Leukoc Biol. 2012;92:753-64.

10. Gordon S, Martinez FO. Alternative activation of macrophages: mechanism and functions. Immunity. 2010;32:593-604.

11. Andrews AL, Holloway JW, Holgate ST, Davies DE. IL-4 receptor alpha is an important modulator of IL-4 and IL-13 receptor binding: implications for the development of therapeutic targets. J Immunol. 2006;176:7456-61.

12. Idzerda RL, March CJ, Mosley B, Lyman SD, Vanden Bos T, Gimpel SD, et al. Human interleukin 4 receptor confers biological responsiveness and defines a novel receptor superfamily. J Exp Med. 1990;171:861-73.

13. Russell SM, Keegan AD, Harada N, Nakamura $Y$, Noguchi $M$, Leland $P$, et al. Interleukin-2 receptor gamma chain: a functional component of the interleukin-4 receptor. Science. 1993;262:1880-3.

14. Obiri NI, Debinski W, Leonard WJ, Puri RK. Receptor for interleukin 13. Interaction with interleukin 4 by a mechanism that does not involve the common gamma chain shared by receptors for interleukins 2, 4, 7, 9, and 15. J Biol Chem. 1995;270:8797-804.

15. Junttila IS, Creusot RJ, Moraga I, Bates DL, Wong MT, Alonso MN, et al. Redirecting cell-type specific cytokine responses with engineered interleukin- 4 superkines. Nat Chem Biol. 2012;8:990-8.

16. McCormick SM, Heller NM. Commentary: IL-4 and IL-13 receptors and signaling. Cytokine. 2015;75:38-50.

17. Pritchard MA, Baker E, Whitmore SA, Sutherland GR, Idzerda RL, Park LS, et al. The interleukin-4 receptor gene (IL4R) maps to $16 \mathrm{p} 11.2-16 \mathrm{p} 12.1$ in human and to the distal region of mouse chromosome 7. Genomics. 1991;10:801-6.

18. Mito N, Hosoda T, Kato C, Sato K. Change of cytokine balance in diet-induced obese mice. Metabolism. 2000;49:1295-300.

19. Ji Y, Sun S, Xia S, Yang L, Li X, Qi L. Short term high fat diet challenge promotes alternative macrophage polarization in adipose tissue via natural killer $T$ cells and interleukin-4. J Biol Chem. 2012;287:24378-86.

20. Ricardo-Gonzalez RR, Red Eagle A, Odegaard Jl, Jouihan H, Morel CR, Heredia JE, et al. IL-4/STAT6 immune axis regulates peripheral nutrient metabolism and insulin sensitivity. Proc Natl Acad Sci USA. 2010;107:22617-22622.

21. Tsao $\mathrm{CH}$, Shiau MY, Chuang PH, Chang YH, Hwang J. Interleukin-4 regulates lipid metabolism by inhibiting adipogenesis and promoting lipolysis. J Lipid Res. 2014:55:385-97.

22. Lizcano F, Vargas D, Gomez A, Torrado A. Human ADMC-derived adipocyte thermogenic capacity is regulated by IL-4 receptor. Stem Cells Int. 2017;2017:2767916.

23. Fischer K, Ruiz HH, Jhun K, Finan B, Oberlin DJ, van der Heide V, et al. Alternatively activated macrophages do not synthesize catecholamines or contribute to adipose tissue adaptive thermogenesis. Nat Med. 2017;23:623-630.

24. Cappelletti M, Presicce P, Lawson MJ, Chaturvedi V, Stankiewicz TE, Vanoni S, et al. Type I interferons regulate susceptibility to inflammation-induced preterm birth. JCI Insight. 2017;2:e91288.

25. Giles DA, Moreno-Fernandez ME, Stankiewicz TE, Graspeuntner S, Cappelletti M, $\mathrm{Wu} D$, et al. Thermoneutral housing exacerbates nonalcoholic fatty liver disease in mice and allows for sex-independent disease modeling. Nat Med. 2017:23:829-838.

26. Harley IT, Stankiewicz TE, Giles DA, Softic S, Flick LM, Cappelletti M, et al. IL-17 signaling accelerates the progression of nonalcoholic fatty liver disease in mice. Hepatology. 2014;59:1830-9.

27. Moreno-Fernandez ME et al. Peroxisomal beta-oxidation regulates whole body metabolism, inflammatory vigor, and pathogenesis of nonalcoholic fatty liver disease. JCI Insight. 2018;3:e93626.

28. Chan CC, Damen M, Moreno-Fernandez ME, Stankiewicz TE, Cappelletti M, Alarcon PC, et al. Type I interferon sensing unlocks dormant adipocyte inflammatory potential. Nat Commun. 2020;11:2745.
29. Kohli R, Kirby M, Xanthakos SA, Softic S, Feldstein AE, Saxena V, et al. Highfructose, medium chain trans fat diet induces liver fibrosis and elevates plasma coenzyme Q9 in a novel murine model of obesity and nonalcoholic steatohepatitis. Hepatology. 2010;52:934-44.

30. Castañeda TR, Abplanalp W, Um SH, Pfluger PT, Schrott B, Brown K, et al. Metabolic control by S6 kinases depends on dietary lipids. PLoS One. 2012;7: e32631.

31. Giles DA, Moreno-Fernandez ME, Stankiewicz TE, Cappelletti M, Huppert SS, Iwakura Y, et al. Regulation of inflammation by IL-17A and IL-17F modulates nonalcoholic fatty liver disease pathogenesis. PLoS One. 2016;11:e0149783.

32. Softic S, Meyer JG, Wang GX, Gupta MK, Batista TM, Lauritzen H, et al. Dietary sugars alter hepatic fatty acid oxidation via transcriptional and post-translational modifications of mitochondrial proteins. Cell Metab. 2019;30:735-753 e4.

33. Softic S, Boucher J, Solheim MH, Fujisaka S, Haering MF, Homan EP, et al. Lipodystrophy due to adipose tissue-specific insulin receptor knockout results in progressive NAFLD. Diabetes. 2016;65:2187-200.

34. Tschöp MH, Speakman JR, Arch JR, Auwerx J, Brüning JC, Chan L, et al. A guide to analysis of mouse energy metabolism. Nat Methods. 2011;9:57-63.

35. Neves AL, Coelho J, Couto L, Leite-Moreira A, Roncon-Albuquerque R Jr. Metabolic endotoxemia: a molecular link between obesity and cardiovascular risk. J Mol Endocrinol. 2013;51:R51-64.

36. Ito M, Suzuki J, Tsujioka S, Sasaki M, Gomori A, Shirakura T, et al. Longitudinal analysis of murine steatohepatitis model induced by chronic exposure to high-fat diet. Hepatol Res. 2007;37:50-7.

37. Draznin B. Molecular mechanisms of insulin resistance: serine phosphorylation of insulin receptor substrate-1 and increased expression of p85alpha: the two sides of a coin. Diabetes. 2006;55:2392-7.

38. Wong RH, Sul HS. Insulin signaling in fatty acid and fat synthesis: a transcriptional perspective. Curr Opin Pharmacol. 2010;10:684-91.

39. Grabherr F, Grander C, Effenberger M, Adolph TE, Tilg H. Gut dysfunction and non-alcoholic fatty liver disease. Front Endocrinol (Lausanne). 2019;10:611.

40. Tappy L, Le KA, Tran C, Paquot N. Fructose and metabolic diseases: new findings, new questions. Nutrition. 2010;26:1044-9.

41. Junttila IS. Tuning the cytokine responses: an update on interleukin (IL)-4 and IL13 receptor complexes. Front Immunol. 2018;9:888.

42. Dufort FJ, Bleiman BF, Gumina MR, Blair D, Wagner DJ, Roberts MF, et al. Cutting edge: IL-4-mediated protection of primary $B$ lymphocytes from apoptosis via Stat6-dependent regulation of glycolytic metabolism. J Immunol. 2007;179:4953-7.

43. Bray GA, Popkin BM. Sugar consumption by Americans and obesity are both too high-are they connected? Response to letter by John White, PhD. Pediatr Obes. 2014;9:e78-9.

44. Klurfeld DM, Foreyt J, Angelopoulos TJ, Rippe JM. Lack of evidence for high fructose corn syrup as the cause of the obesity epidemic. Int J Obes (Lond). 2013;37:771-3.

45. Zhang DM, Jiao RQ, Kong LD. High dietary fructose: direct or indirect dangerous factors disturbing tissue and organ functions. Nutrients. 2017;9:4.

46. Shi J, Fan J, Su Q, Yang Z. Cytokines and abnormal glucose and lipid metabolism. Front Endocrinol. 2019;10:703

47. Inagaki T, Dutchak P, Zhao G, Ding X, Gautron L, Parameswara V, et al. Endocrine regulation of the fasting response by PPARalpha-mediated induction of fibroblast growth factor 21. Cell Metab. 2007;5:415-25.

48. Serra D, Mera P, Malandrino MI, Mir JF, Herrero L. Mitochondrial fatty acid oxidation in obesity. Antioxid Redox Signal. 2013;19:269-84.

49. Ter Horst KW, Serlie MJ. Fructose consumption, lipogenesis, and non-alcoholic fatty liver disease. Nutrients. 2017;9:9.

50. Flannery C, Dufour S, Rabol R, Shulman Gl, Petersen KF. Skeletal muscle insulin resistance promotes increased hepatic de novo lipogenesis, hyperlipidemia, and hepatic steatosis in the elderly. Diabetes. 2012;61:2711-7.

51. Chen MZ, Hudson CA, Vincent EE, de Berker DA, May MT, Hers I, et al. Akt phosphorylation on Thr308 but not on Ser473 correlates with Akt protein kinase activity in human non-small cell lung cancer. Br J Cancer. 2011;104:1755-61.

52. Zamorano J, Wang HY, Wang LM, Pierce JH, Keegan AD. IL-4 protects cells from apoptosis via the insulin receptor substrate pathway and a second independent signaling pathway. J Immunol. 1996;157:4926-34.

53. Perry RJ, Samuel VT, Petersen KF, Shulman GI. The role of hepatic lipids in hepatic insulin resistance and type 2 diabetes. Nature. 2014;510:84-91.

54. Hirst SJ, Hallsworth MP, Peng Q, Lee TH. Selective induction of eotaxin release by interleukin-13 or interleukin-4 in human airway smooth muscle cells is synergistic with interleukin-1beta and is mediated by the interleukin-4 receptor alpha-chain. Am J Respir Crit Care Med. 2002;165:1161-71.

55. Guillot C, Coathalem H, Chetritt J, David A, Lowenstein P, Gilbert E, et al. Lethal hepatitis after gene transfer of IL-4 in the liver is independent of immune responses and dependent on apoptosis of hepatocytes: a rodent model of IL-4induced hepatitis. J Immunol. 2001;166:5225-35. 
56. Goenka S, Kaplan MH. Transcriptional regulation by STAT6. Immunol Res. 2011;50:87-96.

57. Leavy O. Cytokines: Regulating energy stores. Nat Rev Immunol. 2011;11:76.

58. Bao K, Reinhardt RL. The differential expression of IL-4 and IL-13 and its impact on type-2 immunity. Cytokine. 2015;75:25-37.

59. Zhu J, Cote-Sierra J, Guo L, Paul WE. Stat5 activation plays a critical role in Th2 differentiation. Immunity. 2003;19:739-48.

60. Delgoffe GM, Pollizzi KN, Waickman AT, Heikamp E, Meyers DJ, Horton MR, et al. The kinase mTOR regulates the differentiation of helper $T$ cells through the selective activation of signaling by mTORC1 and mTORC2. Nat Immunol. 2011;12:295-303.

61. Chan CC, Harley ITW, Pfluger PT, Trompette A, Stankiewicz TE, Allen JL, et al. A BAFF/APRIL axis regulates obesogenic diet-driven weight gain. Nat Commun. $2021 ; 12$.

62. Moreno-Fernandez ME, Giles DA, Oates JR, Chan CC, Damen M.S.M.A, Doll JR, et al. PKM2-dependent metabolic skewing of hepatic Th17 cells regulates pathogenesis of non-alcoholic fatty liver disease. Cell Metab. 2021;33: 1187-1204.e9.

\section{ACKNOWLEDGEMENTS}

This study was supported, in part, by National Institutes of Health $(\mathrm{NIH})$ grant R01DK099222 (to SD); American Diabetes Association (ADA) grant 1-18-IBS-100 (to SD); Department of Defense (DoD) grant W81XWH2010392 (to SD); NIH grant R01DK099222-02S1 (associated with SD and MEM-F); American Heart Association (AHA) grants 17POST33650045 and ADA 1-19-PMF-019 (associated with MEMF); CCRF Endowed Scholar Award (to S.D.); The Arnold W. Strauss Fellow Award (to J.R.D.); NIH grant T32Al118697 and T32GM063483-14 (associated with CCC); and NIH PHS grant P30 DK078392 (associated with SD)

\section{AUTHOR CONTRIBUTIONS}

M.S.M.A.D., T.E.S., S.P., R.N.H., C.C.C., and M.E.M.-F. participated in data generation. M.S.M.A.D., T.E.S., S.P., R.N.H., C.C.C., M.E.M.-F., J.R.D., D.R.H., S.S. and S.D. participated in data analysis, interpretation, provided materials and technical support and participated in review of the manuscript. S.D. obtained the funding. M.S.M.A.D.,
S.S. and S.D. participated in the conception and design of the study and wrote the manuscript.

\section{COMPETING INTERESTS}

S.D. is a consultant for Janssen Research \& Development.

\section{ADDITIONAL INFORMATION}

Supplementary information The online version contains supplementary material available at https://doi.org/10.1038/s41366-021-00902-6.

Correspondence and requests for materials should be addressed to S.D.

Reprints and permission information is available at http://www.nature.com/ reprints

Publisher's note Springer Nature remains neutral with regard to jurisdictional claims in published maps and institutional affiliations.

(i) Open Access This article is licensed under a Creative Commons Attribution 4.0 International License, which permits use, sharing, adaptation, distribution and reproduction in any medium or format, as long as you give appropriate credit to the original author(s) and the source, provide a link to the Creative Commons license, and indicate if changes were made. The images or other third party material in this article are included in the article's Creative Commons license, unless indicated otherwise in a credit line to the material. If material is not included in the article's Creative Commons license and your intended use is not permitted by statutory regulation or exceeds the permitted use, you will need to obtain permission directly from the copyright holder. To view a copy of this license, visit http://creativecommons. org/licenses/by/4.0/.

(c) The Author(s) 2021 